\title{
Comparison of qualities and capabilities of the "EUROSTAG" software and the Hybrid Real Time Power System Simulator
}

\author{
Alexey Maltsev ${ }^{1, *}$, Ruslan $\mathrm{Ufa}^{1}$, and Nikolay Ruban ${ }^{1}$ \\ ${ }^{1}$ National Research Tomsk Polytechnic University, 634050 Tomsk, Russia
}

\begin{abstract}
To compare the capabilities of the "EUROSTAG" software and the Hybrid Real Time Power System Simulator, simulation of the transient process in both complexes was carried out. The results show which of these complexes is best suited for various tasks.
\end{abstract}

\section{Introduction}

Nowadays electric power systems (EPS) become more complex due to the introduction of FACTS devices, HVDC systems, distributed power production technologies and renewable power sources. Actual is, firstly, the need to ensure uninterrupted operation in the context of the complexity of the network, and secondly, to obtain accurate information about the processes in the EPS. The acquisition of sufficiently complete information provides the effective solution of a wide range of research, design and operation tasks of the EPS.

The main analysis tools of the electric power systems are information-measuring complexes (IIC) and simulation systems. The use of IIC has such drawbacks as high laboriousness of analysis of oscillograms of emergency processes with low observability of the EPS, the limited application of results when the configuration of this EPS is changed and in other power systems, in cases of occurrence of previously disturbed effects and a large time expenditure due to the inability to conduct large-scale full-scale tests in EPS $[1,2,3]$. Thereby, the main analysis tool of the electric power systems' work is simulation. At the same time, special attention is paid to the modeling of dynamic transient processes, since the parameters of transient processes that arise, especially in emergency modes, determine the stability and reliability of the system.

One of the most prevalent modeling tools is "EUROSTAG" software that was developed by TRACTEBEL and ELECTRICITE DE FRANCE [4]. This complex implements a digital approach to modeling.

In Power Grid Simulation Lab the Hybrid Real Time Power System Simulator (HRTSim) was developed which is based on hybrid simulation technology $[5,6]$.

The purpose of this work is comparison of the simulation results in the "EUROSTAG" and in the Hybrid Real Time Power System Simulator.

\footnotetext{
* Corresponding author: maltsevaleksey@mail.ru
} 


\section{Analysis of models of equipment realized in "EUROSTAG" and in the Hybrid Real Time Power System Simulator}

The mathematical model of synchronous machines realized in "EUROSTAG" is based on the classical Park-Gorev theory, and two models are realized:

- Model with the damper winding in the d-axis and two damper windings in the q-axis.

- Model with no damper windings [4].

The load in "EUROSTAG" is modeled by a constant power in the steady-state mode. In the transient mode, a load model with voltage and frequency dependence is realized, a model of the controlled load taking into account the action of the tap changer of the stepdown transformer and the distribution network model [4].

As a mathematical model of synchronous machines realized in HRTSim, a complete system of Park-Gorev equations of high accuracy is used, together with equations for the formation of three-phase coordinates $a, b, c$ and equations for the mutual transformation of system variables d, q and a, b, c. Increased accuracy is achieved by modeling a larger number of damper circuits and taking into account the dependence of their parameters on frequency, namely three contours along the d-axis and four contours along the q-axis $[3,7$, 8].

The load model realized in HRTSim includes equivalent asynchronous and synchronous motors, the generalized load described by the dependences of the active and reactive power of this load on frequency and voltage, taking into account the voltage regulation range $[3,9$, $10]$.

\section{Results of simulation}

On the figure 1 there is the scheme of the grid, which includes generator (G), step-up transformer $(\mathrm{T})$, transmission line (TL) and the load (L).

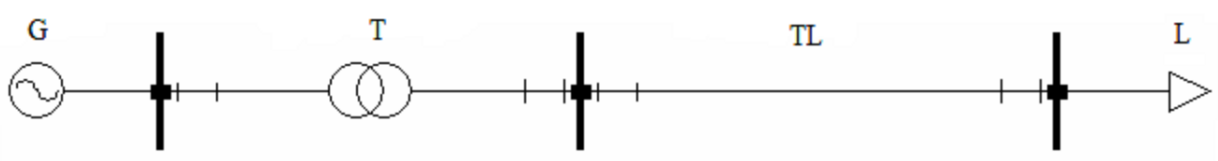

Fig. 1. The scheme of the grid.

In "EUROSTAG", the tests are carried out according to the following scenario: at a time of 10 seconds, a sudden increase in power is produced at the load node up to a time of 100 seconds.

When simulating a synchronous generator, the full model type is used without saturation, with 3 windings (the Park-Gorev equation).The load is modeled by constant resistance. Figure 2 shows the generator voltage and power consumption curves.

Further tests are carried out in a similar scenario in HRTSim. Thus it is possible to take into account fluctuations of parameters of a mode, or to not consider them, having translated the generator in an infinite bus. Figure 3 shows oscillograms of the voltage of generator and infinite bus.

From the graphs obtained, it can be seen that the nature of the process is similar for modeling in the HRTSim and in "EUROSTAG". The voltage curve of the endless power node is close to the voltage curve received in "EUROSTAG", that testifies to the convergence of calculations in these complexes. However, according to the generator voltage plot obtained in the HRTSim, it can be seen that the voltage fluctuations, which are always present in power systems, increase their scope with increasing load. Figure 4 shows a frequency oscillogram in the power system. 

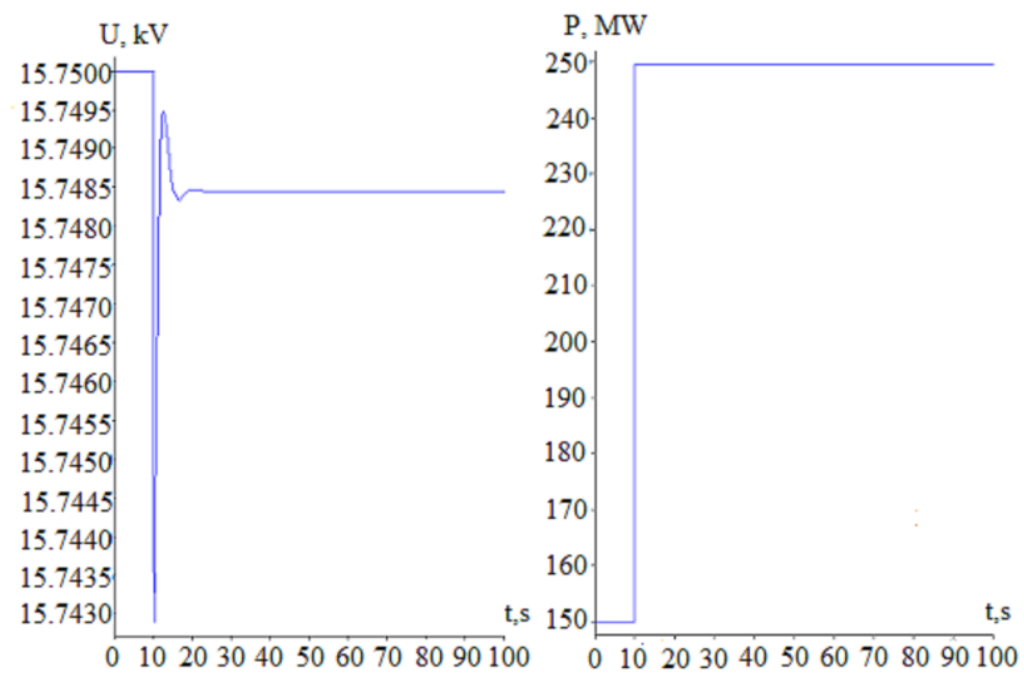

Fig. 2. Generator's voltage and power consumption curves.

$\mathrm{U}, \mathrm{kV}$

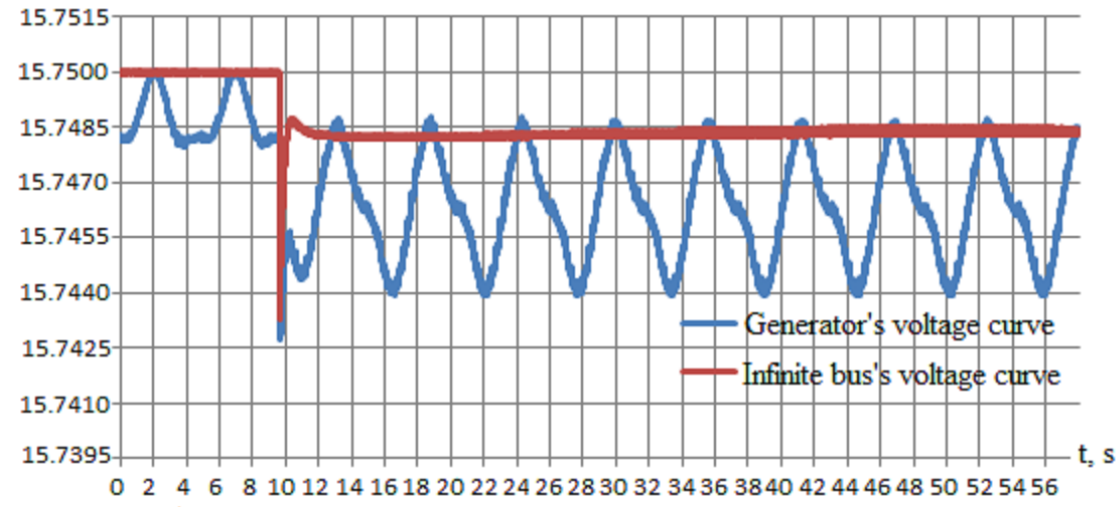

Fig. 3. Oscillograms received in Hybrid Real Time Power System Simulator.

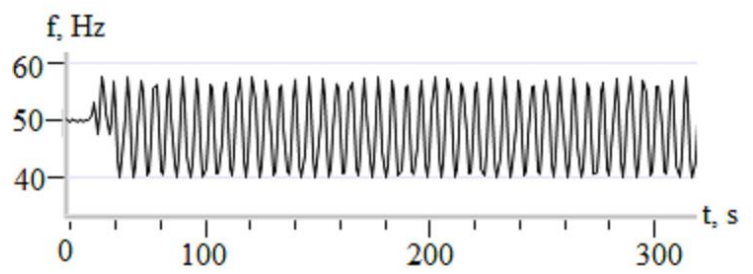

Fig.4. Frequency curve obtained in the Hybrid Real Time Power System Simulator.

From the curve it can be seen, that as a result of the power drop, firstly, the sweep of the fluctuations increases, and secondly, the oscillations occur relatively lower than in the initial mode, that is, the frequency in the power system decreases.

As a result, the generator drops out of synchronism, the power system collapses.

Figure 5 show a graph of frequency in the presence of infinite bus and the frequency graph obtained in "EUROSTAG". 


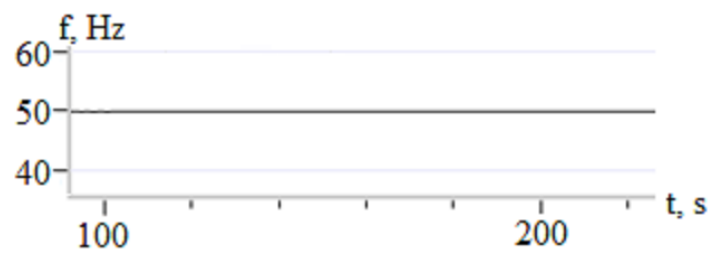

a)

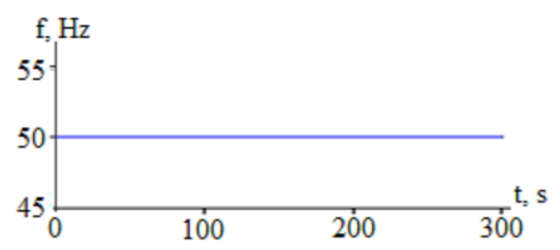

b)

Fig. 5. Graph of frequency in the presence of infinite bus (a) and graph of frequency obtained in "EUROSTAG" (b)

When calculating in "EUROSTAG" and in the presence of infinite bus it is impossible to judge the frequency changes, because infinite bus maintains the frequency value to constant.

As a result of this work it can be seen that with the help of the HRTSim it is possible to obtain more detailed information about the behavior of the power system under the influence of various perturbations. This complex allows us to see not only the nature of the transient process and the new steady-state regime, but also to get the information about the fluctuations of the regime itself and, accordingly, its stability, that is, it gives an idea of the dynamic stability of the energy system and its static stability. "EUROSTAG" models separately steady-state modes, not taking into account the oscillations occurring in the power system, it calculates directly the transients, gives the information only about the dynamic stability.

This work was supported by the Non-profit Partnership "Global Energy" under the project No. MG- 2017/04/1 "Developing a hardware and software platform for all-regimes real-time simulation of intelligent electric power systems".

\section{References}

1. M. Khatir, S. Ahmed Zidi, S. Hadjeri, J. Electrical Eng. 61, 1 (2010)

2. R.L. Sellick, M. Åkerberg, 10th IET Int. Conf. AC DC Power Transmission. Birmingham (2012)

3. M.V. Andreev, A.O. Sulaymanov, A.A. Suvorov, MATEC Web Conf. 37, 1 (2015), DOI: $10.1051 /$ matecconf $/ 20153701001$

4. M. Stubbe, A. Bihain, J. Deuse, J.C. Baader, IEEE Trans. Power systems, 4 (1988)

5. A.A. Suvorov, Yu.S. Borovikiv, A.S. Gusev, A.O. Sulaymanov, M.V. Andreev, N.Yu. Ruban, R.A. Ufa, Electrical eng. 99, (2017), DOI: 10.1007/s00202-016-0464-4

6. A.A. Suvorov, A.S. Gusev, A.O. Sulaymanov, O.V. Suslova, MATEC Web Conf. 91, 1 (2016), DOI: 10.1051/matecconf/20179101052

7. A.S. Gusev, A.A. Suvorov, A.O. Sulaymanov, MATEC Web Conf. 37, 1 (2015), DOI: 10.1051/matecconf/20153701023

8. Yu.S. Borovikov, A.O. Sulaymanov, M.V. Andreev, IOP Conf. Series: Mater. Sci. Eng. 93, 5 (2015), DOI: 10.1088/1757-899X/93/1/012001

9. Yu.S. Borovikov, A.V. Prokhorov, M.V. Andreev, 7th Int. Forum Strategic Techol. 2, 604 (2012), DOI: 10.1109/IFOST.2012.6357822

10. A.S. Gusev, A.A. Suvorov, A.O. Sulaymanov, IOP Conf. Series: Mater. Sci. Eng. 93, 5 (2015), DOI: 10.1088/1757-899X/93/1/012016 